\title{
Misplaced intrauterine contraceptive devices: a case report
}

\author{
Nidhi D. Thakkar*, Jaydeep D. Hindocha
}

Department of Obstetrics and Gynaecology, Baroda Medical College, Ms University, Vadodara, Gujarat, India

Received: 13 October 2021

Accepted: 09 November 2021

\section{*Correspondence:}

Dr. Nidhi D. Thakkar,

E-mail: nidhi_thakkar240@yahoo.com

Copyright: ( $)$ the author(s), publisher and licensee Medip Academy. This is an open-access article distributed under the terms of the Creative Commons Attribution Non-Commercial License, which permits unrestricted non-commercial use, distribution, and reproduction in any medium, provided the original work is properly cited.

\begin{abstract}
Contraception is a new topic gaining attention in country like India and a new proposed area of research. Intrauterine contraceptive devices (IUCDs) are one contraceptive method requiring less efforts and having more efficacy. 'Misplaced IUCD' is one of the rare and the most dreadful complication of IUCD insertion. Clinically, it can present as having pain, bleeding, recurrent pregnancy loss or can be asymptomatic. This is a case report of a 40 year old P4A1L4 female who presented to us with suspicion of misplaced IUCD without clinical symptoms. Clinical examination and radiological investigations made a diagnosis of misplaced IUCD and laparoscopy confirmed it. Laparoscopically misplaced IUCD was removed.
\end{abstract}

Keywords: Contraception, Misplaced IUCD, X-ray, Computed tomographic scan, Laparoscopy

\section{INTRODUCTION}

There are many temporary and permanent methods of contraception. One of it is intrauterine contraceptive device (IUCD). Its advantages of being a one-time procedure without need of regular use of tablets or barrier contraceptives and it is reversible. Copper containing IUCDs are provided free of cost by the National family welfare programme in India. Newer IUCDs exhibit more safety, efficacy and lesser side effects.

Misplaced IUCD is when thread is not visible at cervical os. ${ }^{1}$ Cases of misplaced IUCDs may present with variable range of signs and symptoms. This is a case where patient conceived with copper-T in situ and even during instrumental evacuation of products of conception leaving the copper- $\mathrm{T}$ in body and patient was diagnosed having misplaced IUCD accidently. Patient was asymptomatic throughout.

\section{CASE REPORT}

A 40 year old P4A1L4 married female came to gynaecology outpatient department (OPD) after being referred for misplaced IUCD from other facility. On presentation she had no complaints related to copper-T insertion. She had delivered four female children as full term normal vaginal delivery over the span of 15 years and underwent copper-T insertion on 28 February 2019 at a tertiary care centre during immediate postpartum period of last child birth. Patient again conceived with copper-T in situ after one year of copper-T insertion and underwent surgical management for termination of first trimester pregnancy with gestational age being 5 weeks and 4 days at the tertiary care hospital, where she was told that copper$\mathrm{T}$ was still in situ even after surgical evacuation of products of conception.

Her past, personal and family history were not significant. Her general and per abdominal examination were also not significant. Per speculum examination revealed a normal cervix and vagina. No threads of copper-T were visible. On per vaginal examination, uterus was normal sized, anteverted and bilateral fornices were clear.

Her ultrasonography (USG) was done, but was not suggestive of any copper- $T$ and then her $\mathrm{X}$ ray-pelvis was done which was consistent with negative history of 
expulsion of copper-T. Her contrast enhanced computed tomography (CECT) of abdomen and pelvis was done suggestive of complete extrauterine displacement of IUCD in anterior perivesicle fat and wall enhancing fluid density collection around the stem of IUCD p/o abscess formation with suspicious hypodense tract in right anterolateral wall of uterine fundus.

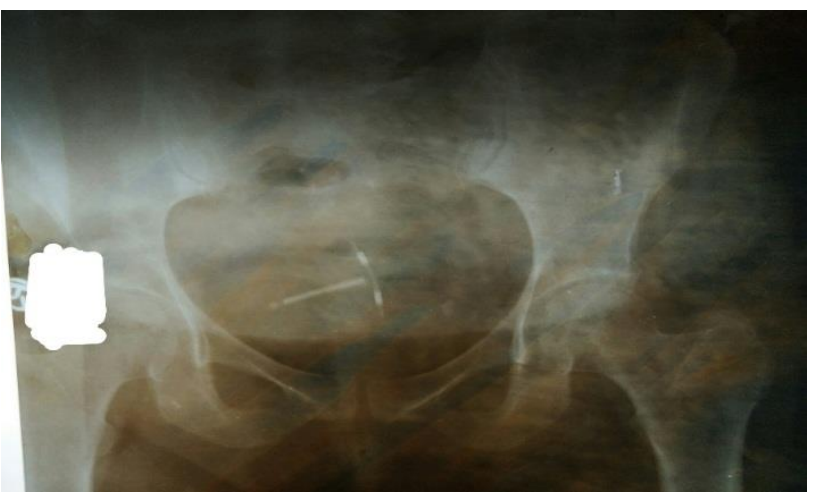

Figure 1: X-ray pelvis showing $\mathrm{Cu}-\mathrm{T}$.

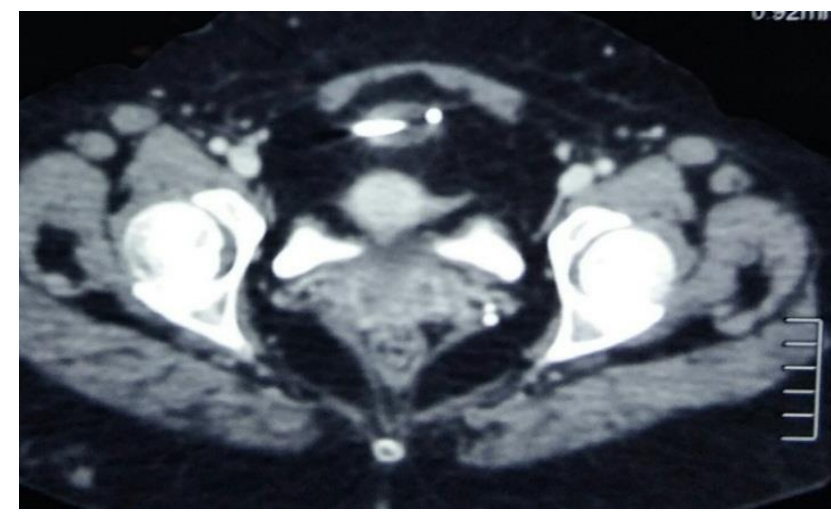

Figure 2: CECT abdomen and pelvis showing misplaced IUCD.

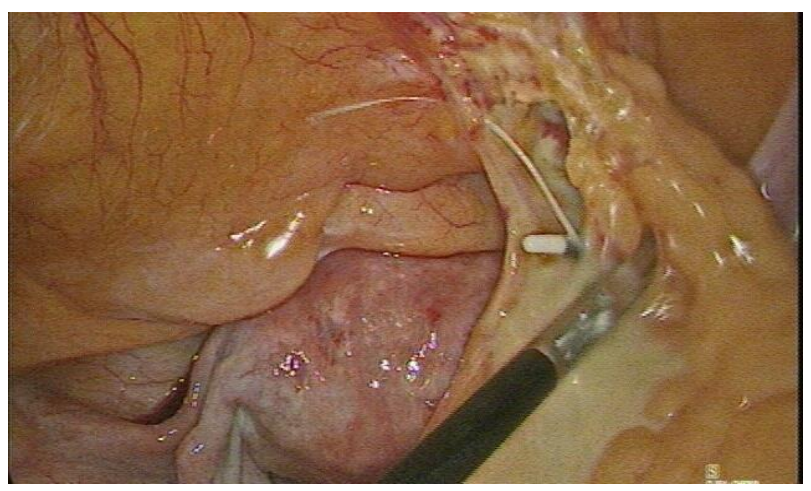

Figure 3: IUCD in omentum with adhesions in peritoneal cavity.

Operative laparoscopy for copper $\mathrm{t}$ removal was done. Copper-T was found in peritoneal cavity in omentum with granuloma formation around it, which was removed and copper-T was retrieved.

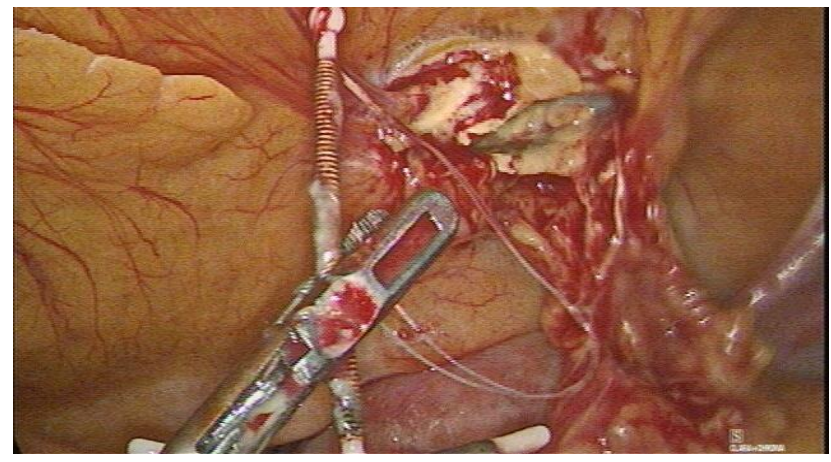

Figure 4: Laparoscopic removal of $\mathrm{Cu}-\mathrm{T}$.

\section{DISCUSSION}

Over last few years, need for contraception and its use has been increased significantly perhaps due to increased literacy rate and improved health system in periphery. The rate of IUCD insertion as well as postpartum IUCD insertion rates have raised so as the complications arising from them.

Perforation of uterus is a serious but uncommon complication of IUCD insertion. The incidence of uterine perforations from IUCD insertion may be $0.5-1 / 1000$ IUCD insertions. ${ }^{2}$ Chances of perforation are high mainly during insertion. Perforation may not cause any symptoms and may remain unnoticed in about $85 \%$ cases. $^{3}$ Sharp abdominal pain during insertion, missing thread, recurrent pregnancy loss and vaginal bleeding may be indicators of perforation. Sometimes IUCDs may cause cervical perforation which may be partial and the stem of IUCD may protrude through the cervix into vagina causing dysparenuia and the device may be felt by patient. When completely transmigrating IUCD reaches to peritoneal cavity they may be reported from bowel causing perforations, bowel obstruction, bladder perforation, rectal strictures, rectovaginal fistulas. ${ }^{4}$

For diagnosis, per speculum and per vaginal examinations are followed by sound insertion. CT scan is preferred modality to diagnose partial or complete perforation by IUCD. Anteroposterior and lateral X-ray abdomen and pelvis can be performed after inserting uterine sound to localize the relative position of perforated IUCD in relation to the uterine sound. As newer modalities, hysteroscopy and laparoscopy can be used as both diagnostic and therapeutic modality.

Misplaced IUCDs have to be removed even if asymptomatic as they trigger excessive peritoneal inflammation leading to adhesion formation with omentum, intestines and other adjoining structures. ${ }^{5}$ If misplaced IUCD invades bowel or bladder, assistance from surgeons may be needed and laparotomy may mandate. For misplaced IUCD in peritoneal cavity, laparotomy, laparoscopy or combined hysterolaparoscopy may be needed. 


\section{CONCLUSION}

To spread awareness regarding contraception and to fulfill unmet need of contraception is very big target in country like India. That is why it is necessary to pay attention to even smaller complications of any method as these type of complications may negatively influence other people's reviews. Health care workers must be trained adequately to improve quality of different contraceptive methods. Patients and health care workers must be educated about various presentations and early signs of complications of any methods. Systemic retrograde follow up in terms of research studies should be organized to identify risk factors for misplaced IUCD in real cases like time of insertion, particular type of IUCD, substandard quality of health care system, inadequately trained health care workers.

Funding: No funding sources

Conflict of interest: None declared

Ethical approval: Not required

\section{REFERENCES}

1. Sankareswari R, Indira, Geetha K, Vani S. Misplaced and migrated iucd: a case report. J Evol Med Dent Sci. 2014;3(25):7031-5.

2. Kriplani A, Garg P, Sharma M, Agarwal N. Laparoscopic removal of extrauterine iucd using fluoroscopy guidance: a case report. J Gynaecol Surg. 2005;21(1):29-30.

3. Nigam A, Biswas R, Mishra A. Misplaced intrauterine contraceptive device: an enigma. Open Access J Contracept. 2011;2:1-3.

4. Key TC, Kreutner AK. Gastrointestinal complications of modern intrauterine contraceptive device. Obstet Gynecol. 1980;55:239-44.

5. Treisser A, Colau JC. Causes, diagnosis and treatment of uterine perforations by intrauterine devices. J Gynaecol Obstet Biol Reported. 1978;7:837-47.

Cite this article as: Thakkar ND, Hindocha JD. Misplaced intrauterine contraceptive devices: a case report. Int J Reprod Contracept Obstet Gynecol 2021;10:4596-8. 